\title{
Foods Inducing Typical Gastroesophageal Reflux Disease Symptoms in Korea
}

\author{
Jung Wan Choe, Moon Kyung Joo, Hyo Jung Kim, Beom Jae Lee, Ji Hoon Kim, Jong Eun Yeon, Jong-Jae Park, Jae Seon Kim, \\ Kwan Soo Byun, and Young-Tae Bak*
}

Department of Gastroenterology, Korea University Guro Hospital, Seoul, Korea

\section{Background/Aims}

Several specific foods are known to precipitate gastroesophageal reflux disease (GERD) symptoms and GERD patients are usually advised to avoid such foods. However, foods consumed daily are quite variable according to regions, cultures, etc. This study was done to elucidate the food items which induce typical GERD symptoms in Korean patients.

\section{Methods}

One hundred and twenty-six Korean patients with weekly typical GERD symptoms were asked to mark all food items that induced typical GERD symptoms from a list containing 152 typical foods consumed daily in Korea. All patients underwent upper gastrointestinal endoscopy followed by 24-hour ambulatory esophageal pH monitoring. The definition of "GERD" was if either of the 2 studies revealed evidence of GERD, and "possible GERD" if both studies were negative.

\section{Results}

One hundred and twenty-six cases (51 GERD and 75 possible GERD) were enrolled. In 19 (37.3\%) of 51 GERD cases and in 17 (22.7\%) of 75 possible GERD cases, foods inducing typical GERD symptoms were identified. In the GERD group $(n=19)$, frequent symptominducers were hot spicy stews, rice cakes, ramen noodles, fried foods, and topokki. In the possible GERD group $(n=17)$, frequent symptom-inducers were hot spicy stews, fried foods, doughnuts, breads, ramen noodles, coffee, pizza, topokki, rice cakes, champon noodles, and hotdogs.

\section{Conclusions}

In one-third of GERD patients, foods inducing typical symptoms were identified. Hot spicy stews, rice cakes, ramen noodles, fried foods, and topokki were the foods frequently inducing typical symptoms in Korea. The list of foods frequently inducing typical GERD symptoms needs to be modified based on their own local experiences.

(J Neurogastroenterol Motil 2017;23:363-369)

\section{Key Words}

Food; Gastroesophageal reflux; Korea; Symptom assessment

Received: July 28, 2016 Revised: October 17, 2016 Accepted: November 13, 2016

(a) This is an Open Access article distributed under the terms of the Creative Commons Attribution Non-Commercial License (http://creativecommons. org/licenses/by-nc/4.0) which permits unrestricted non-commercial use, distribution, and reproduction in any medium, provided the original work is properly cited.

*Correspondence: Young-Tae Bak, MD

Department of Gastroenterology, Korea University Guro Hospital, 148 Gurodong-ro, Guro-gu, Seoul 08308, Korea Tel: +82-2-2626-1778, Fax: +82-504-366-6381, E-mail: drbakyt@korea.ac.kr 


\section{Introduction}

Gastroesophageal reflux disease (GERD) is characterized by abnormal reflux of the gastric contents into the esophagus. ${ }^{1}$ In most patients with GERD, reflux of gastric juice commonly causes heartburn and regurgitation. ${ }^{2}$ Barrett's esophagus, which is a premalignant lesion for esophageal adenocarcinoma, is considered one of the most important complications of GERD. ${ }^{3}$

These troublesome symptoms and complications are the main drivers for GERD patients to seek medical attention. The conditions, such as male gender, a presence of a hiatal hernia, history of Helicobacter pylori eradication, current alcohol intake, and abdominal obesity, are known as risk factors for GERD., Dietary factors traditionally have been thought to induce or worsen GERD. GERD symptoms are commonly reported postprandially, suggesting that some specific diet components are more likely to induce symptoms. ${ }^{4}$ With the introduction of 24-hour $\mathrm{pH}$ monitoring, it has been objectively shown that postprandial reflux is important in reflux symptom profiles. ${ }^{6,7}$ However, there have been few attempts to measure the effect of specific food stuffs that might provoke or increase gastroesophageal reflux. Although several studies have reported that high-fat foods, spicy foods, chocolate, mint, and citrus fruits are closely related to GERD symptoms, ${ }^{8-10}$ the daily consumed foods are quite variable according to race, geographic specificity, diet habit, and culture. The conflicting conditions may cause differences in food-induced GERD symptoms between Asian and Western populations. Therefore, dietary recommendations should be based on local experiences. According to a recent Korean study, dietary categories aggravating typical or atypical GERD symptoms in possible GERD cases were noodles, fatty meals, caffeinated drinks, spicy foods, alcohol, breads, carbonated drinks, and sweets. ${ }^{11}$

This study was performed to investigate food items that are frequently consumed daily and may be responsible for inducing typical GERD symptoms in confirmed GERD patients in their daily lives in Korea.

\section{Materials and Methods}

One hundred and twenty-six consecutive subjects who visited our Digestive Disease Center between February 2009 and September 2014 due to at least weekly typical GERD symptoms (heartburn or regurgitation) for at least 3 months were recruited into this prospective study. Subjects were excluded if they had other significant gastrointestinal diseases (for example, active peptic ulcer disease, infectious conditions of the intestine and gastric malignancy), a history of gastrectomy or severe health problems. Exclusion criteria also included any use of NSAIDs, oral steroids or aspirin, use of proton pump inhibitors or histamine $\mathrm{H} 2$ receptor antagonists over the preceding 3 months, and current pregnancy. All subjects provided written informed consent prior to the investigation.

All patients underwent upper gastrointestinal endoscopy to assess the presence and extent of esophageal mucosal breaks. Thereafter, 24-hour ambulatory esophageal $\mathrm{pH}$ monitoring was carried out. Patients with GERD symptoms were divided into 2 groups according to the results of endoscopy and $\mathrm{pH}$ monitoring; "GERD" if either of the 2 studies revealed evidence of GERD, and "possible GERD" if both studies were negative.

The patients were asked during their first visit whether they experienced their typical GERD symptoms induced by any specific food intake for the preceding 3 months. Then they marked all food items which induced their typical GERD symptoms from a food list containing 152 foods usually consumed daily by Koreans. The food list was made including all individually collected daily food consumption lists from more than 20 hospital staffs and patients. Considering the possibility of omission of any foods, if the patients could not find any symptom-inducing foods of their own from the list, they were instructed to add such foods freely to the list. In addition, they crossed out all food items that they had not consumed for the preceding 3 months from the list.

Symptom-inducing foods were categorized into 2 groups: "frequent symptom-inducers" if they induced symptom(s) in half or more occasions of consumption, and "occasional symptominducers" if they induced symptom(s) in less than half occasions of consumption. When any food induced typical GERD symptoms in half or more patients of the group, it was regarded as a meaningful culprit food.

All statistical analyses were conducted using the SPSS statistical software (version 20.0; IBM Corp, Armonk, NY, USA). $P$-values less than 0.05 were considered statistically significant. The data with continuous variables were expressed as mean \pm standard deviation. The estimated internal consistency of the food list questionnaire was assessed through Cronbach's alpha coefficients.

Written informed consent was obtained from all participants. This study received approval from the institutional review board of Korea University Guro Hospital.

\section{Results}

A total of 126 patients completed the study. Among these sub- 
jects, the age of 51 GERD patients ranged from 27 to 72 years, and the 75 possible GERD patients were aged 17 to 79 years. In $19(37.3 \%)$ out of the 51 GERD cases and in 17 (22.7\%) out of the 75 possible GERD cases, foods inducing typical GERD symptoms were identified (Figure). The Cronbach's alpha value of the overall questionnaire was 0.77 (95\% confidence interval 0.75 0.78 ) among the 152 food items and, therefore, it was acceptable for internal consistency.

Table 1 shows clinical characteristics of the 4 subgroups according to the presence of mucosal breaks and/or pathologic refluxes and symptom-inducing foods. There were no differences in age, gender, height, weight, and body mass index (BMI) between patients with and without symptom-inducing foods in both GERD and possible GERD groups, except a female predominance in the possible GERD group with symptom-inducing foods. Among the patients without symptom-inducing foods, the BMI in GERD patients was significantly greater than that in possible GERD patients (24.9 \pm 4.6 vs $22.5 \pm 3.7, P=0.007)$.

In the GERD group, foods that frequently induced typical
GERD symptoms in half or more patients were hot spicy stews, rice cakes, ramen noodles, fried foods, and topokki (stir-fried rice cakes). Foods that frequently or occasionally induced GERD symptoms in half or more patients included biscuits, breads, handpulled dough soups, hamburgers, doughnuts, spicy noodles with vegetables and seafoods (champon), noodles with stir-fried bean paste (jajangmyeon), alcohols, carbonated beverages, pizzas, mandarins, plain noodles, oranges, and milk (Table 2).

In the possible GERD group, foods that frequently induced typical GERD symptoms in half or more patients were hot spicy stews, fried foods, doughnuts, breads, ramen noodles, coffee, pizzas, topokki, rice cakes, champon, and hotdogs. Moreover, cola, oranges, alcohols, hamburgers, jajangmyeon, hand-pulled dough soups, dumplings, red beans, green tea, and rice cake soups were added to the list of foods that frequently or occasionally induced GERD symptoms in half or more patients (Table 3).

In all confirmed or possible GERD cases, foods that frequently induced typical GERD symptoms in half or more patients were hot spicy stews, rice cakes, ramen noodles, fried foods, breads, and

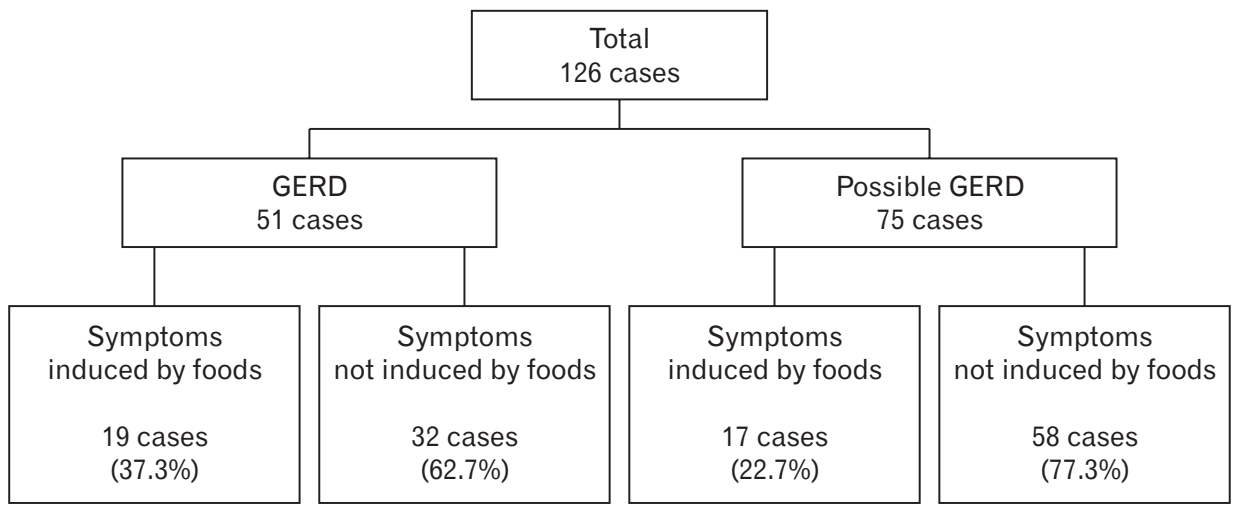

Figure. Enrolled cases. GERD, gastroesophageal reflux disease.

Table 1. Baseline Characteristics According to Status of Gastroesophageal Reflux Disease and Symptom-inducing Foods

\begin{tabular}{|c|c|c|c|c|c|c|}
\hline & \multicolumn{2}{|c|}{ GERD } & \multirow[b]{2}{*}{$P$-value } & \multicolumn{2}{|c|}{ Possible GERD } & \multirow[b]{2}{*}{$P$-value } \\
\hline & $\begin{array}{l}\text { Food }(+) \\
(n=19)\end{array}$ & $\begin{array}{l}\text { Food }(-) \\
(\mathrm{n}=32)\end{array}$ & & $\begin{array}{c}\text { Food }(+) \\
(n=17)\end{array}$ & $\begin{array}{l}\text { Food }(-) \\
(\mathrm{n}=58)\end{array}$ & \\
\hline Age (mean $\pm \mathrm{SD})$ & $55.5 \pm 9.8$ & $52.7 \pm 11.5$ & 0.358 & $50.8 \pm 13.1$ & $52.5 \pm 14.1$ & 0.670 \\
\hline Gender $(\mathrm{M} / \mathrm{F})$ & $7 / 12$ & $12 / 20$ & 0.963 & $1 / 16$ & $20 / 38$ & 0.021 \\
\hline Height (mean $\pm \mathrm{SD}, \mathrm{cm})$ & $160.0 \pm 10.2$ & $161.5 \pm 7.9$ & 0.554 & $159.3 \pm 6.7$ & $161.2 \pm 8.2$ & 0.182 \\
\hline Weight (mean $\pm \mathrm{SD}, \mathrm{kg})$ & $62.3 \pm 11.4$ & $65.1 \pm 13.4$ & 0.454 & $58.5 \pm 7.8$ & $59.5 \pm 13.0$ & 0.375 \\
\hline $\mathrm{BMI}($ mean $\pm \mathrm{SD})$ & $24.3 \pm 3.2$ & $24.9 \pm 4.6$ & 0.609 & $23.1 \pm 2.1$ & $22.5 \pm 3.7$ & 0.809 \\
\hline
\end{tabular}

GERD, gastroesophageal reflux disease; M, male; F, female; BMI, body mass index.

GERD patients with at least weekly typical GERD symptoms were divided into 2 groups according to the results of endoscopy and pH monitoring; "GERD" if either of the 2 studies revealed evidence of GERD, and "possible GERD" if both studies were negative. 
Table 2. List of Food Items That Frequently or Occasionally Induced Typical Gastroesophageal Reflux Disease Symptoms and Percentage of Patients in Gastroesophageal Reflux Disease Cases

\begin{tabular}{|c|c|c|c|}
\hline \multicolumn{4}{|c|}{ GERD patients $(\mathrm{n}=19)$} \\
\hline \multicolumn{2}{|c|}{ Frequent inducers } & \multicolumn{2}{|c|}{ Frequent or occasional inducers } \\
\hline Food items & Patients (\%) & Food items & Patients (\%) \\
\hline Hot spicy stews & 63.2 & Hot spicy stews & 84.2 \\
\hline Rice cakes & 63.2 & Ramen noodles & 84.2 \\
\hline Ramen noodles & 57.9 & Fried foods & 75.0 \\
\hline Fried foods & 50.0 & Rice cakes & 73.7 \\
\hline \multirow[t]{15}{*}{ Topokki } & 50.0 & Biscuits & 64.3 \\
\hline & & Breads & 63.2 \\
\hline & & Hand-pulled dough soups & 60.0 \\
\hline & & Topokki & 56.3 \\
\hline & & Hamburgers & 56.3 \\
\hline & & Doughnuts & 55.6 \\
\hline & & Champon & 55.6 \\
\hline & & Jajangmyeon & 55.6 \\
\hline & & Alcohols & 54.5 \\
\hline & & Fanta beverages & 54.5 \\
\hline & & Pizzas & 53.3 \\
\hline & & Mandarins & 52.6 \\
\hline & & Plain noodles & 52.6 \\
\hline & & Oranges & 50.0 \\
\hline & & Milk & 50.0 \\
\hline
\end{tabular}

GERD, gastroesophageal reflux disease; Champon, spicy noodles with vegetables and seafoods; Jajangmyeon, noodles with stir-fried bean paste.

topokki. Foods that frequently or occasionally induced GERD symptoms in half or more patients additionally included pizzas, doughnuts, coffee, hand-pulled dough soups, champon, hamburgers, alcohols, jajangmyeon, oranges, biscuits, cola, and plain noodles (Table 4).

\section{Discussion}

It is commonly accepted that meals can trigger symptoms in GERD patients, but accurate and objective data are limited. Most of the recommendations on changes in dietary habits are not strongly supported by objective measurements. The relationship between foods and GERD in the Korean population still remains unclear. The results of our study show that hot spicy stews, rice cakes, ramen noodles, fried foods, and topokki are frequently inducing typical GERD symptoms in Korean GERD patients.

Although some studies reported that some nutrients and foods are related to the presence of GERD symptoms in Western patients, ${ }^{10,12}$ there are no well-organized data regarding foods as-
Table 3. List of Food Items That Frequently or Occasionally Induced Typical Gastroesophageal Reflux Disease Symptoms and Percentage of the Patients in Possible Gastroesophageal Reflux Disease Cases

\begin{tabular}{|c|c|c|c|}
\hline \multicolumn{4}{|c|}{ Possible GERD patients $(\mathrm{n}=17)$} \\
\hline \multicolumn{2}{|c|}{ Frequent inducers } & \multicolumn{2}{|c|}{ Frequent or occasional inducers } \\
\hline Food items & Patients (\%) & Food items & Patients (\%) \\
\hline Hot spicy stews & 76.9 & Fried foods & 88.9 \\
\hline Fried foods & 66.7 & Hot spicy stews & 84.6 \\
\hline Doughnuts & 66.7 & Topokki & 81.8 \\
\hline Breads & 62.5 & Breads & 81.3 \\
\hline Ramen noodles & 57.1 & Pizzas & 77.8 \\
\hline Coffee & 57.1 & Rice cakes & 73.3 \\
\hline Pizzas & 55.6 & Coffee & 71.4 \\
\hline Topokki & 54.5 & Doughnuts & 66.7 \\
\hline Rice cakes & 53.3 & Ramen noodles & 64.3 \\
\hline Champon & 50.0 & Hotdogs & 62.5 \\
\hline \multirow[t]{11}{*}{ Hotdogs } & 50.0 & Cola & 60.0 \\
\hline & & Oranges & 58.3 \\
\hline & & Champon & 57.1 \\
\hline & & Alcohols & 57.1 \\
\hline & & Hamburgers & 57.1 \\
\hline & & Jajangmyeon & 55.6 \\
\hline & & Hand-pulled dough soup & 53.8 \\
\hline & & Dumplings & 50.0 \\
\hline & & Red beans & 50.0 \\
\hline & & Green tea & 50.0 \\
\hline & & Rice cake soups & 50.0 \\
\hline
\end{tabular}

GERD, gastroesophageal reflux disease.

sociated with GERD symptoms in Asian patients. In Europe and the United States, some investigators have shown that dietary fat, cholesterol, saturated fatty acid, dietary fiber, and other nutrients are associated with GERD. ${ }^{10,12}$ They believe that both improved socioeconomic status and the westernized pattern of diet consumption may be associated with the increasing prevalence of GERD in Asians. ${ }^{13}$ However, the currently available data do not support a strong relationship between GERD and dietary factors in Asians including Koreans. Taken together, our findings support a recommendation for Korean patients with GERD and possible GERD to avoid specific foods because GERD symptoms appear more frequently after consumption of the common symptom-inducing foods. This study also systematically evaluated the role of daily consumed Korean traditional foods as well as westernized foods in GERD symptom generation.

Supporting data exist regarding some specific meals in relation to GERD symptoms. The role of fat in symptom generation has been demonstrated in several studies. ${ }^{6,14-16}$ In some clinical stud- 
Table 4. List of Food Items That Frequently or Occasionally Induced Typical Gastroesophageal Reflux Disease Symptoms, and Percentage of Patients with Gastroesophageal Reflux Disease and Possible Gastroesophageal Reflux Disease Cases

\begin{tabular}{|c|c|c|c|}
\hline \multicolumn{4}{|c|}{ GERD or possible GERD patients $(\mathrm{n}=36)$} \\
\hline \multicolumn{2}{|c|}{ Frequent inducers } & \multicolumn{2}{|c|}{ Frequent or occasional inducers } \\
\hline Food items & Patients (\%) & Food items & Patients $(\%)$ \\
\hline Hot spicy stews & 68.8 & Hot spicy stews & 84.4 \\
\hline Rice cakes & 58.8 & Fried foods & 80.0 \\
\hline Ramen noodles & 57.6 & Ramen noodles & 75.8 \\
\hline Fried foods & 56.0 & Rice cakes & 73.5 \\
\hline Breads & 54.3 & Breads & 71.4 \\
\hline Topokki & 51.9 & Topokki & 66.7 \\
\hline & & Pizzas & 62.5 \\
\hline & & Doughnuts & 59.1 \\
\hline & & Coffee & 58.1 \\
\hline & & Hand-pulled dough soups & 57.1 \\
\hline & & Champon & 56.3 \\
\hline & & Hamburgers & 56.0 \\
\hline & & Alcohols & 55.6 \\
\hline & & Jajangmyeon & 54.8 \\
\hline & & Oranges & 53.1 \\
\hline & & Biscuits & 51.9 \\
\hline & & Cola & 51.9 \\
\hline & & Plain noodles & 50.0 \\
\hline
\end{tabular}

GERD, gastroesophageal reflux disease.

ies, it was shown that esophageal $\mathrm{pH}$ monitoring provides direct evidence on the association between dietary fat and acid reflux, and that high-fat meal decreases the lower esophageal sphincter pressure, increases the rate of transient lower esophageal sphincter relaxation, and delays the gastric emptying, ${ }^{5}$ which may lead to a greater incidence of reflux. ${ }^{14,15}$ Spicy foods attributable to direct irritation of already inflamed lower esophageal mucosa may exacerbate heartburn. ${ }^{17}$ Red pepper, which contains the neurotoxin capsaicin, has been shown to delay gastric emptying, ${ }^{18,19}$ and it can possibly provoke reflux. Some previous studies have found that an increase in salt consumption was associated with GERD, which was attributed to the inhibited gastric motor activity and delayed gastric emptying after high salt intake. ${ }^{20,21}$ It was also found that a low-carbohydrate diet reduces distal esophageal acid exposure in 24-hour $\mathrm{pH}$ testing and improves GERD symptoms. ${ }^{22}$ In a study, ingestion of lactose resulted in an increased number of transient lower esophageal sphincter relaxations, increased reflux episodes, higher esophageal acid exposure, and more severe GERD symptoms in healthy volunteers. $^{23}$ Similarly, our results also revealed a relationship between the above mentioned tastes or nutrients and GERD symptoms. Many GERD patients are more likely to experience a perceived reflux event when they eat some fatty, spicy, salty foods, and meals with high carbohydrate content. Ramen noodles, hot spicy stews, and topokki are typically spicy and salty Korean traditional foods. Rice cake and bread contain high carbohydrate nutrients. These are the foods to which Koreans have easy access and they are frequently used for main meal replacement.

Conflicting data exist regarding the roles of specific meals in relation to GERD symptoms. In several studies investigating the effect of diet on gastroesophageal reflux, the results have not been consistent. ${ }^{24-26}$ Certain eating habits, such as eating quickly and irregularly, eating big meals, eating between meals, or eating directly before sleeping, individualized acid hypersensitivity and psychological stress may contribute to the appearance of symptoms. ${ }^{11,27,28}$ As shown in our study, females were predominant among possible GERD patients with food related symptoms. It may be that females have a tendency to have a sensitive esophagus or to relate to psychological stress.

This is the first study that systematically and prospectively evaluated the role of 152 variable diets with frequency in symptom generation among patients with GERD and possible GERD by permitting multiple choices and using a comprehensive diet tool. In addition, many possible GERD patients, who are commonly encountered in one-third to one-half of the Korean population with GERD symptoms, were enrolled. ${ }^{29}$ Hence, this study can reflect the actual aspects of the racial, geographic, and cultural specificities in Korean patients with GERD symptoms. Interestingly, most symptom-inducing foods are Korean traditional foods which have been consumed since a long time ago. The recent increase in GERD prevalence in Korea cannot be fully explained by the change to westernized foods. Finally, although a high BMI is a well-known independent risk factor for esophageal erosions, it did not affect esophageal inflammation particularly in patients with food-induced symptoms in our study. This finding is in contrast with patients without food-related symptoms.

This study could be used as a reference for the development and validation of diet recommendations for GERD patients that are applicable to Korean patients. A recent cross-sectional study demonstrated that GERD patients consumed symptom-inducing foods more frequently than in asymptomatic individuals. This suggested that dietary modification could be effective in reducing and managing GERD symptoms. ${ }^{30}$ Based on our study, a dietary education program for GERD patients could be developed using figures of foods which are familiar to the patients and are encountered daily. It 
could help physicians and patients to gain an insight into the symptoms possibly related to foods and reinsure avoidance of these foods. Regardless of the emergence of potent medicines (such as improved proton pump inhibitors, transient lower esophageal sphincter relaxation reducers, mucosal protectants, and esophageal-specific pain modulators), ${ }^{31}$ correctable diet modifications should be emphasized. Avoiding such foods may be important for maintaining patients in a symptom-free state which was attained with medications, although it may not be helpful to induce healing of GERD. Dietary advice such as avoidance of symptom-inducing foods may not be very difficult to follow and can reduce unnecessary medical costs.

Our study has some limitations. First, although we used a rather short time window of 3 months, the recall bias and residual confounding factors (eating habits, lifestyle, and genetic risk factors) might have influenced the results. Second, this study has a limitation stemming from its small sample size. The reason why we could not recruit more cases was that we included only new patients with typical GERD symptoms while excluding users of NSAIDs, oral steroids or aspirin, users of proton pump inhibitors or histamine $\mathrm{H} 2$ receptor antagonists over the preceding 3 months, and we included only those who underwent both upper gastrointestinal endoscopy and 24-hour ambulatory $\mathrm{pH}$ monitoring. Further researches with a larger scale multicenter national study seem to warrant better clarification of the relationship between foods and GERD symptoms in Korea.

In conclusion, hot spicy stews, rice cakes, ramen noodles, fried foods, and topokki are most common foods that induce typical GERD symptoms in Korean GERD patients. The list of food items that produce typical GERD symptoms in patients from Asian countries needs to be revised substantially from the Western literature based on their own local experiences.

\section{Financial support: None.}

\section{Conflicts of interest: None.}

Author contributions: Jung Wan Choe: data analysis, data interpretation, and writing the manuscript; Young-Tae Bak: data acquisition, data analysis, data interpretation, and drafting the manuscript; and Moon Kyung Joo, Hyo Jung Kim, Beom Jae Lee, Ji Hoon Kim, Jong Eun Yeon, Jong-Jae Park, Jae Seon Kim, and Kwan Soo Byun: data acquisition and critical revision of the manuscript.

\section{References}

1. Vakil N, Van Zanten SV, Kahrilas P, Dent J, Jones R. The Montreal definition and classification of gastroesophageal reflux disease: a global evidence-based consensus. Am J Gastroenterol 2006;101:1900-1920.

2. Kao SS, Chen WC, Hsu PI, et al. The frequencies of gastroesophageal and extragastroesophageal symptoms in patients with mild erosive esophagitis, severe erosive esophagitis, and barrett's esophagus in Taiwan. Gastroenterol Res Pract 2013;2013:480325.

3. Falk GW. Gastroesophageal reflux disease and Barrett's esophagus. Endoscopy 2001;33:109-118.

4. Dore MP, Maragkoudakis E, Fraley K, et al. Diet, lifestyle and gender in gastro-esophageal reflux disease. Dig Dis Sci 2008;53:2027-2032.

5. Kulig M, Nocon M, Vieth M, et al. Risk factors of gastroesophageal reflux disease: methodology and first epidemiological results of the ProGERD study. J Clin Epidemiol 2004;57:580-589.

6. Shapiro M, Green C, Bautista JM, et al. Assessment of dietary nutrients that influence perception of intra-oesophageal acid reflux events in patients with gastro-oesophageal reflux disease. Aliment Pharmacol Ther 2007;25:93-101.

7. Ravi K, Francis DL, See JA, Geno DM, Katzka DA. The effects of a weakly acidic meal on gastric buffering and postprandial gastro-oesophageal reflux. Aliment Pharmacol Ther 2011;34:568-575.

8. Schönfeld J, Evans DF. [Fat, spices and gastro-oesophageal reflux]. Z Gastroenterol 2007;45:171-175. [German]

9. Vemulapalli R. Diet and lifestyle modifications in the management of gastroesophageal reflux disease. Nutr Clin Pract 2008;23:293-298.

10. Wu P, Zhao XH, Ai ZS, et al. Dietary intake and risk for reflux esophagitis: a case-control study. Gastroenterol Res Pract 2013;2013:691026.

11. Song JH, Chung SJ, Lee JH, et al. Relationship between gastroesophageal reflux symptoms and dietary factors in Korea. J Neurogastroenterol Motil 2011;17:54-60.

12. Festi D, Scaioli E, Baldi F, et al. Body weight, lifestyle, dietary habits and gastroesophageal reflux disease. World J Gastroenterol 2009;15:16901701.

13. Wu JC. Gastroesophageal reflux disease: an Asian perspective. J Gastroenterol Hepatol 2008;23:1785-1793.

14. Iwakiri K, Kobayashi M, Kotoyori M, Yamada H, Sugiura T, Nakagawa Y. Relationship between postprandial esophageal acid exposure and meal volume and fat content. Dig Dis Sci 1996;41:926-930.

15. Holloway RH, Lyrenas E, Ireland A, Dent J. Effect of intraduodenal fat on lower oesophageal sphincter function and gastro-oesophageal reflux. Gut 1997;40:449-453.

16. Meyer JH, Lembo A, Elashoff JD, Fass R, Mayer EA. Duodenal fat intensifies the perception of heartburn. Gut 2001;49:624-628.

17. Milke P, Diaz A, Valdovinos MA, Moran S. Gastroesophageal reflux in healthy subjects induced by two different species of chilli (Capsicum annum). Dig Dis 2006;24:184-188.

18. Park HJ, Na SK, Lee SI, Kang JK, Park IS. The effect of red pepper and capsaicin on gastric emptying in human volunteers. Gastroenterology 1998;114:A818. 
19. Horowitz M, Wishart J, Maddox A, Russo A. The effect of chilli on gastrointestinal transit. J Gastroenterol Hepatol 1992;7:52-56.

20. Tanaka T, Mizumoto A, Muramatsu S, et al. Postprandial normal saline intake delays gastric emptying of solids in conscious dogs: partial involvement of CCK in its mechanism. Dig Dis Sci 1999;44:1516-1524.

21. Nilsson M, Johnsen R, Ye W, Hveem K, Lagergren J. Lifestyle related risk factors in the aetiology of gastro-oesophageal reflux. Gut 2004;53:1730-1735.

22. Austin GL, Thiny MT, Westman EC, Yancy WS Jr, Shaheen NJ. A very low-carbohydrate diet improves gastroesophageal reflux and its symptoms. Dig Dis Sci 2006;51:1307-1312.

23. Piche T, Zerbib F, Varannes SB, et al. Modulation by colonic fermentation of LES function in humans. Am J Physiol Gastrointest Liver Physiol 2000;278:G578-G584.

24. Zheng Z, Nordenstedt H, Pedersen NL, Lagergren J, Ye W. Lifestyle factors and risk for symptomatic gastroesophageal reflux in monozygotic twins. Gastroenterology 2007;132:87-95.

25. Nandurkar S, Locke Gr 3rd, Fett S, Zinsmeister AR, Cameron AJ, Talley NJ. Relationship between body mass index, diet, exercise and gastrooesophageal reflux symptoms in a community. Aliment Pharmacol Ther
2004;20:497-505.

26. Ruhl CE, Everhart JE. Overweight, but not high dietary fat intake, increases risk of gastroesophageal reflux disease hospitalization: the NHANES I epidemiologic followup study. First national health and nutrition ezamination survey. Ann Epidemiol 1999;9:424-435.

27. Yang JH, Kang HS, Lee SY, et al. Recurrence of gastroesophageal reflux disease correlated with a short dinner-to-bedtime interval. J Gastroenterol Hepatol 2014;29:730-735.

28. Matsuki N, Fujita T, Watanabe N, et al. Lifestyle factors associated with gastroesophageal reflux disease in the Japanese population. J Gastroenterol 2013;48:340-349.

29. Kim N, Lee SW, Cho SI, et al. The prevalence of and risk factors for erosive oesophagitis and non-erosive reflux disease: a nationwide multicentre prospective study in Korea. Aliment Pharmacol Ther 2008;27:173-185.

30. Kubo A, Block G, Quesenberry CP, Buffler P, Corley DA. Dietary guideline adherence for gastroesophageal reflux disease. BMC Gastroenterol 2014;14:144.

31. Maradey-Romero C, Fass R. New and future drug development for gastroesophageal reflux disease. J Neurogastroenterol Motil 2014;20:6-16. 